On the next morning the temperature fell to $98^{\circ}$, only reaching $99.4^{\circ}$ in the evening, and on the following and subsequent day it remained absolutely normal. All traces of erysipelas had disappeared from the face, the leucocyte count dropped to 7,000, and the patient looked and felt completely convalescent. Suppuration rapidly diminished, and completely disappeared in a fortnight.

The improvement in the patient's condition was remarkably dramatic, and I think undoubtedly due to the specific action of the erysipelas antitixin on the streptococcal infection.

REFERENCE.

Iourn. Amer. Med. Assoc., December 7th, 1929

\section{PSITTACOSIS WITH ENCEPHALITIC SYMPTOMS}

BY

HEXRY J. KRICHEFSKI, M.B., B.S.LOND., RFSIDENT MHDICAL OFFICER TO THE BRITISH HOSPITAL, PORT SAID.

Dr. A. P. Thompson (Lancet, February 22nd, 1930, p. 396) describes a rase (No. 8) of psittacosis in which the nervoll symptoms were marked enough to suggest a diagnosis of enceplatitis. Below is a description of a similar rase occurring in Port Said. This is the first recorded case of the disease in Egypt.

The patient, Mrs. H., aged 32, a British resident of Port Said, had begun to feel ill on the eveuing of February 10th, 1930, with headache, cough, and vomiting. She was seen by a local practitioner, and as her condition became steadily worse during the next few days and no definite diagnosis coul! be arrived at, she was admitted to the British Hospital on February 15th.

On admission the patient looked ill, being flushed and bathed in perspiration. She complained of severe headache, especially at the back of the head, and difficulty in speaking and swallowing. She was also slightly delirious. Her temperature was $102.8^{\circ} \mathrm{F}$., pulse rate 114 , and respiration rate 28 . On examination a few moist sounds were heard at the left apex. The right lung was clear and the heart normal. The abdomen was distended, but: not tender on palpation, and the tip of the spleen could just be felt. A trace of albumin was present in the urine. A bilateral Babinski response was elicited, and also Kernig's and Brudzinski's signs. Both knee-jerks were absent, and the fundi were normal. There was no cough or dyspnoea, and no spulum could be obtained.

On February 16th the patient's condition was worse, the temperature being $104^{\circ} \mathrm{F}$. and the pulse rate 98 . She was still complaining of severe headache. Lumbar puncture was performed; the fluid was clear and not under pressure, and it disclosed no ahrormalities on examination. On February i7th she was much worse; the abdominal distension had increaserl, the temperature was $102.6^{\circ} \mathrm{F}$, and the pulse rate 88 . The left apex was now solid, and air entry was practically absent. Coarse crepitations were present over the whole of the left chest. The patient was more delirious, very weak, and unable to speak.

Agglutination tests for " $\mathrm{O}$ " and " $\mathbf{H}$ " agglutinins against B. typhosus and B. paratyphosus $A$ and $B$ wre negative, and it was not possible to demonstrate the presence of specific agglutinins for any member of the biphasic group of salmonella organisms. Blood culture in a variety of media and inoculation experiments were negative. Culture of the faeces and urine resulted in the isolation of $B$. faccalis alkaligencs. It was present in pure culture in the urine. Thompson notes a similar finding in one or two cases. There was a leucocytosis, the number of white blood corpuscles being 15,000 per c.mm.

During the evening of February 17th the patient was seen by another medical man in consultation, and a diagnosis of psiltacosis was made. The patient had iwenty-three birds at home, including three parrots and two love-birds recently acquired. The husband stated that some of the birds had been fighting furiously. Two had died after this disturbanes; probably they had been sick and were killed by the others. All the birds were gassed, and post-mortem examination and a fairly extensive cultural investigation yielded negative results. This does not discount the possibility of the dead bitds having been infected with the virus.

During the next three days coma supervencd; the abdomen became more distended and the temperature remained between $103^{\circ}$ and $104^{\circ} \mathrm{F}$., the pulse being relatively slow. Examination of the fundi showed blurring of the edges of the dises, suggesting a rise of intracranial pressure. The condition of the patient was critical. On the evening of February 21st lumbar puncture was again performed; the fluid was clear, but this time it came out under great pressure, and on examination small numbers of diplococci were seen. The same evening an injection of $30 \mathrm{ccm}$. of polyvalent antipneumococcal serum was given intrathecally. After a rather severe reaction the temperalure fell the next day to $1.00 .2^{2} \mathrm{~F}$. A further $20 \mathrm{cccm}$. of the same serum were then given, intrathecally as before. A mild reaction oceured, during which the temperature rose to $102^{\circ} \mathrm{F}$. and thrm fell to $99^{\circ} \mathrm{F}$. The coma now began to diminish, and the patient seemed much better. The fundi were now normal.

On February $23 \mathrm{rd} 20 \mathrm{c.cm}$. of polyvalent antimeningococcal scrum were given intravenously, and the temperature fell to $98.2^{\circ} \mathrm{F}$. in the next few hours. During the following two weeks the patient slowly gained ground and marle an uninterrupled recovery. On March 4th she was able to sit up in bed and take solid nourishment. At the moment of writing she still has some slight difficulty in articulation, and the fealures are rather inexpressive, rescmbling the mask-like facies seen after encephatitis lethargica. However, both these conditions ai!e improving rapidly, so that in all probability no permanent disability will result.

I have never scen any reference to a rase of psittacosis in which the meningeal symptoms and the general nervous srmptoms were so pronounced. Although an apical lobas pneumonia is always associated with active delirim and some nervous symptoms, I incline to the rlinical-diagnosis of psittarosis, for these reasons:

1. After a week's illness the patient appeared to be as ill as if she were in the third week of enteric fever-she had a brown, furred tongue, sordes on lips, etr.

2. The left lung was solid; ihere was no tubular breathing and hardly any air entry; the patient had no dyspnoea. in cough, and no expectoration; coarse crepitations were present; in fact, the chest condition was more ac'ate than in anv condition I know.

3. A meningitis can develop in any acute condition.

4. The specific serum treatment was hardly sufficient to have worked so remarkable a cure.

5. The nervous symptoms were more those of an encophalit is than of a pure meningitis-for example. the inask-like expression of the face, the early loss of knee-jerks. the double Babinski response, and bulbar paralytic symptoms (speech and swallowing) before the cerebro-spinal fuid was even cloudy or contained abnormal cells or organisms.

6. The impression I gained from this case was that it was a clinical syndrome that I had never met before. I am indebied to Dr. Dolbey and Major Bensted of Cairo for
their kind and valuable assistance in enabling me to prepare this case for publication, and to Dr. R. P. Stewart for permitting mo to publish this report.

\section{TREATMENT OF MEASLES WITH AMIDOPIRIN.}

BY

J. I. COILIFR, Ph.D., B.Sc.Lovd., M.R.C.S., L.R.C.P., FORMERLY ASSISTANT, BIOCHEMICAL DEPARTMENT, MIDDLESEX HOSPITAL.

THEse observations are intended as a preliminary communication on the curative effects of amidoprrin in the treatment of measles. This drug is a white crystalline compound, slightly bitter, and easily soluble in water. According to the French Pharmaceutical codex the maximum single dose is $\mathbf{1 5}$ grains, the naximum in twentyfour lowrs is 45 grains.

In the following case of measles drastic measures seemed to be indicated, and $I$ decided to utilize the powerful antiprretic property of the drug. The discovery that it seemed to exercise an atmest specific artion on the disease itself was fortuitous, and led me to make a search of the literature. I found that Loewenthal' had used the same drug in the treatment of measles, but it does not secm to have been generally adopted.

The patient, a girl aged 8, had a history of whooping-cough in 1928, leaving her with chronic bronchitis. In September, 1929, she liad lobar pneumonia, and while convaleseing, though still weak and coughing, she developed measles. I was called to see her cne afternoon when the rash was just appearing behind the ears and on the forehead. Her temperature was $104.5^{\circ}$; there was marked coryza, and Koplik's spots were present. The pre-existing cough was more severe. She was immediately put on amidopyrin, 5 grains four-hourly day and night. The next morning (about twenty hours after she was first seen) the temperature was down to $100^{\circ}$. Instead of the anticipated profuse eruption only a faint morbilliform rash was showing. The drug was continued 